\title{
Dynamics of Microclimate Conditions in Freestall Barns During Winter - a Case Study from Poland
}

\section{Sabina Angrecka ${ }^{1 *}$, Piotr Herbut ${ }^{1}$, Dorota Godyń ${ }^{2}$, Frederico Márcio Corrêa Vieira ${ }^{3}$, Monika Zwolenik'}

1 Department of Rural Building, University of Agriculture, al. Mickiewicza 24-28, 30-059 Krakow, Poland

2 Department of Cattle Breeding, National Research Institute of Animal Production, ul. Krakowska 1, 32-083 Balice/Krakow, Poland

3 Biometeorology Study Group [GEBIOMET], Universidade Tecnológica Federal do Paraná (UTFPR), Estrada para Boa Esperança, km 04, Comunidade São Cristóvão, Dois Vizinhos, PR 85660-000, Brazil

* Corresponding author's e-mail: s.angrecka@ur.krakow.pl

\begin{abstract}
The climate changes observed in recent years as an increase in the average air temperature influence the microclimatic conditions in dairy barns not only in summer but also in winter. The heat emitted by cows, the orientation of buildings to the cardinal points and farm layout have substantial effect and are additional factors influencing the microclimate in the barns with curtain sidewalls. The aim of the present studies was to determine the effect of atmospheric air temperature and relative humidity on the selected parameters of the indoor microclimate in two neighboring freestall barns in winter. The air temperature and relative humidity sensors were positioned in the barns (A, B) and outdoors. The obtained results were compared with each other. The indoor air temperature recorded in two barns was higher than the outdoor temperature by an average of $2.4^{\circ} \mathrm{C}$ and $2.8^{\circ} \mathrm{C}$, respectively. The greatest difference between the average indoor and the outdoor air temperature was $4.9^{\circ} \mathrm{C}$. Daily analysis indicated that in warm days, the patterns of the air temperature and relative humidity changes were similar in both barns. In turn, during cold days, when the outdoor air temperature was below $0^{\circ} \mathrm{C}$, there was a difference in temperature between both barns, which could result from the position of the buildings towards cardinal points and the heat emitted by cattle influencing the air temperature in the barn. The points where the temperature difference was the highest were located in the leeward part of the building, which was additionally sunlit during the midday hours. Thus, it is recommended to estimate the airflow velocity and sun exposure in different zones of the barn. This would also help to establish the guidelines for the design of new barns in the context of architectural and spatial solutions.
\end{abstract}

Keywords: freestall barns, livestock facilities, environmental control, welfare

\section{INTRODUCTION}

The efficiency of dairy farming depends crucially on the housing system and barn microclimatic conditions [Gaworski and Kowalska, 2013]. The indoor barn environment depends principally on climatic conditions, most of all, on air temperature and relative humidity, intensity of solar radiation and wind speed. Other critical factors include the barn orientation to the cardinal points, existing buildings, geometry and volume of the barn and its ventilation system [Teye et al.,
2008; Herbut et al., 2013; Angrecka et al., 2017]. The impact of atmospheric air temperature and humidity, composing the thermal-humidity system, can be altered especially in winter, due to various factors, including the heat emitted by cattle [Herbut and Angrecka, 2015; DeVoe, 2017]. According to Pedersen and Sallvik [2002], the percent contribution of the heat emitted by cows affecting the barn microenvironment depends on milk yield, locomotor activity of cows and energy value of feed. However, irrespective of the changing ambient temperature, the high-yielding cows 
tend to produce more heat than the less productive or dry cows, which results from high level of metabolism of the former.

Cold stress in cattle in open freestall barns is mostly determined by atmospheric factors [Kadzere et al. 2002]. Combinations of most extreme conditions are particularly undesirable. Although the thermoregulatory mechanism in dairy cows allows them to function at the temperatures exceeding the optimal temperatures, the animals exposed to extreme temperatures show negative changes impairing their welfare in a wider sense [Adamczyk et al., 2015; Pinto et al., 2019; Pilatti et al., 2019]. Cows maintain a high level of production provided that the temperature and humidity are between -5 and $+20^{\circ} \mathrm{C}$ for temperature and 50 to $80 \%$ for relative humidity [Kadzere et al. 2002]. However, it should be borne in mind that very low temperatures in winter, accompanied by a high wind speed can adversely affect the cattle welfare, both on pastures and in barns with curtain sidewalls [Herbut, 2013]. According to Kadzere et al. [2002,] the effect of low indoor air temperature can be reduced by the heat emitted by cows and warming by solar radiation, which increase the average daily temperatures in winter. It can be expected that the climate changes observed in Poland over the last decades, expressed by various factors, including elevated daily average temperatures in winter [Kundzewicz and Matczak, 2012], in combination with the heat emitted by cattle can minimize disadvantageous indoor microclimatic conditions in barns. Nevertheless, there is a lack of information regarding the variability of microclimatic parameters in dairy facilities during winter. Thus, through this present study, the authors aimed to assess the indoor microclimate in two neighbouring barns during winter in Poland.

\section{MATERIALS AND METHODS}

The trial was conducted in two neighbouring steel-framed freestall barns (maximum dimensions: $74.66 \times 14.08 \times 5.18 \mathrm{~m})$ located at the Nidek dairy farm in Poland (19'20' E; 49 $52^{\prime}$ N). The barns (A and B) are parallel to each other and are separated by a feed alley $7.35 \mathrm{~m}$ wide. The barns have a gable roof with a 17-degree pitch. Each barn housed 100 Holstein-Friesian cows. The cows in barn A and B produced approx. $32 \mathrm{~kg}$ milk/day and $40 \mathrm{~kg}$ milk/day, respectively. On the basis of the milk production by individual cows, the heat emitted by each cow kept in barn A and $\mathrm{B}$ was calculated according to the formula given by Pedersen and Sallvik [2002]:

$$
\Phi=5.6 \cdot m^{0,75}+22 \cdot Y_{1}+1.6 \cdot 10^{-5} \cdot p^{3}[\mathrm{~W}]
$$

where: $-m$ - body mass of the cow, $\mathrm{kg}$,

$$
\begin{aligned}
& Y_{1}-\text { milk production, } \mathrm{kg} / \mathrm{d}, \\
& p \text { - days of pregnancy. }
\end{aligned}
$$

Microclimate records were carried out from 9 December 2013 to 13 January 2014. In two barns (A and B), a total of six temperature and relative humidity sensors were positioned (A1-3 and B1-3) (Figure 1). The measurements were taken through Voltcraft DL-181THP sensors with a measurement range from $-40^{\circ} \mathrm{C}$ to $+70^{\circ} \mathrm{C}$ and $0-100 \% \mathrm{RH}$ and measurement accuracy $\pm 1{ }^{\circ} \mathrm{C}$, $\pm 3.5 \%$ RH. In addition, one sensor ( $\mathrm{Z}$ ) was located outdoors in a shaded location in order to record the changes in atmospheric air temperature and relative humidity. The data was recorded at 5 -min intervals. The analysis of the daily average air temperatures in winter (December - March) was carried out on the basis of data from the $\mathrm{Na}-$ tional Research Institute of Meteorology and Water Management (IMWM) for the period 20112016 as measured at the meteorological station in Bielsko Biala located $25 \mathrm{~km}$ away from the dairy farm, where the study was conducted.

\section{RESULTS}

The analysis of the pattern of changes in the average air temperature during the 4 winter months for the period 2011-2016 showed a tendency towards warmer winters. During the analyzed period, the 2013/2014 winter season was the warmest with the average air temperature of $3.8^{\circ} \mathrm{C}$ (Figure 2). The calculations of the heat emitted by cows indicated that the animals housed in barn A and B emitted $1380 \mathrm{~W}$ and $1560 \mathrm{~W}$ on the average, respectively.

The daily average outdoor air temperature during the study period was $5.1^{\circ} \mathrm{C}$, which should be considered high for the winter period in Poland. There were only 5 days when its value fell below $0^{\circ} \mathrm{C}$. The average indoor air temperatures in both barns were $7.5^{\circ} \mathrm{C}$ in barn $\mathrm{A}$ and $8.0^{\circ} \mathrm{C}$ in barn $\mathrm{B}$, which resulted from the heat emitted by the cows. During the assessed period, many days were also characterized by high average relative humidity. The maximum daily values often exceeded 90\% (Figure 3). 
a)

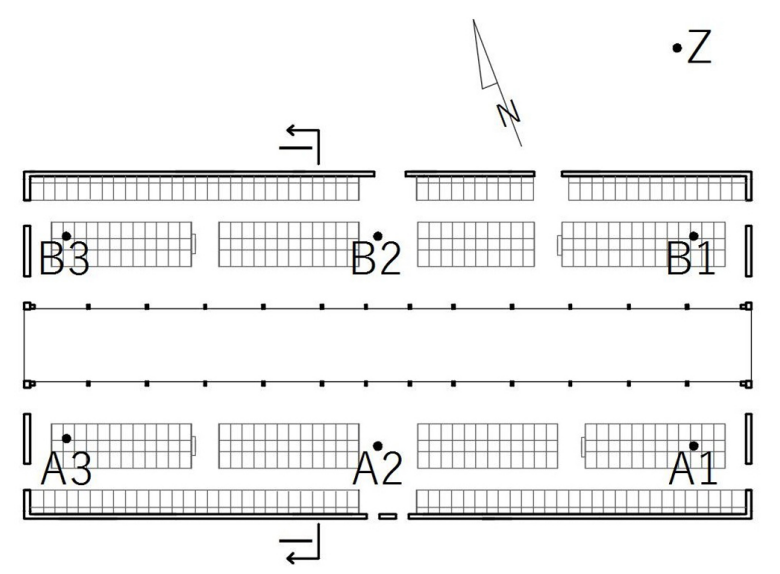

b)

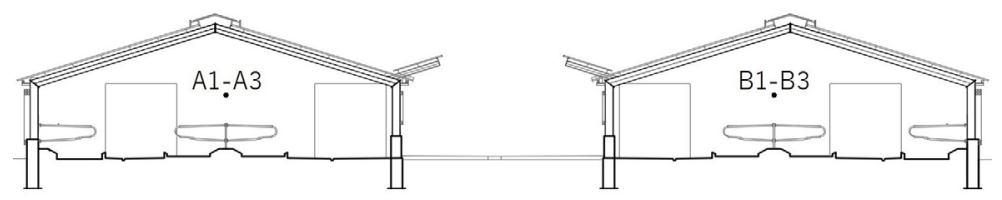

Figure 1. Barn layout with positions of temperature and relative humidity sensors a) floor plan of barns A and B, b) cross-section I - I

The indoor air temperature recorded in barns $\mathrm{A}$ and $\mathrm{B}$ was higher than the outdoor air temperature by an average of $2.4^{\circ} \mathrm{C}$ and $2.8^{\circ} \mathrm{C}$, respectively. The greatest difference in daily temperatures was noted on 19 th December 2013 in barn B. The amplitude between the average indoor air temperature in this building and the outdoor temperature was $4.9^{\circ} \mathrm{C}\left(3.9^{\circ} \mathrm{C}\right.$ in barn A). On the other hand, on 12th January 2014, no difference in trend was recorded between the outdoor and barn B indoor air temperature (daily average was $10^{\circ} \mathrm{C}$ ). The indoor air temperature in barn A was lower than the temperature outdoors by $0.1^{\circ} \mathrm{C}$. It can be noted that the indoor air temperature in barn A was lower by an average of $0.4^{\circ} \mathrm{C}$, whilst the maximum difference was $1.9^{\circ} \mathrm{C}$. The pattern of changes in the air temperature in barn B was very similar as in barn A, but the fluctuations between the sensors in barn A were smaller than in barn B.

On the basis of the daily average outdoor air temperatures, two representative days - cold and warm - were chosen from the whole study period for a more detailed analysis. On the cold day (19 December), the daily average temperature was $-1.6^{\circ} \mathrm{C}$. The daily average indoor temperature in barn $\mathrm{A}$ was $2.5^{\circ} \mathrm{C}$, and in barn $\mathrm{B}-2.9^{\circ} \mathrm{C}$. The highest air temperatures were recorded at measurement points $\mathrm{A} 1$ and $\mathrm{B} 1$, while the lowest at A2 and B2. In both barns the trend was similar, the relative humidity values did not significantly differ between measurement points (max. differences $1.3 \%$ ), while the difference between daily averages was only $0.4 \%$ (Figure 4 ).

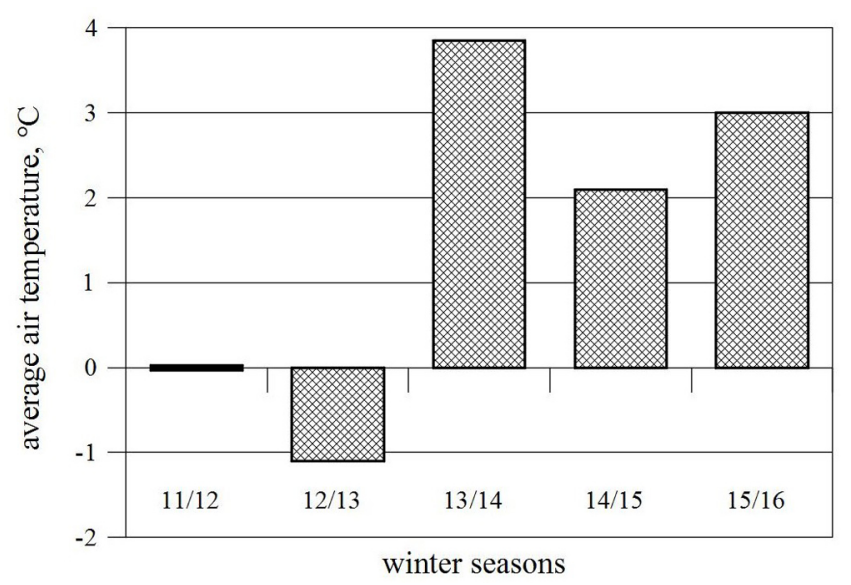

Figure 2. Average winter air temperature in years from 2011 to 2016 


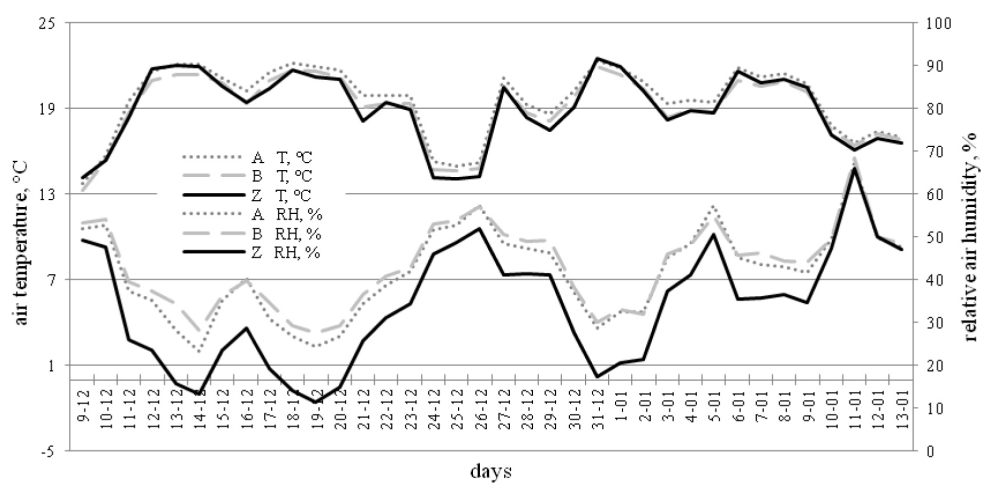

Figure 3. Daily average indoor air temperature and relative humidity in the period from 9 December 2013 to 13 January 2014 in barns A and B and outdoor temperature Z

a)
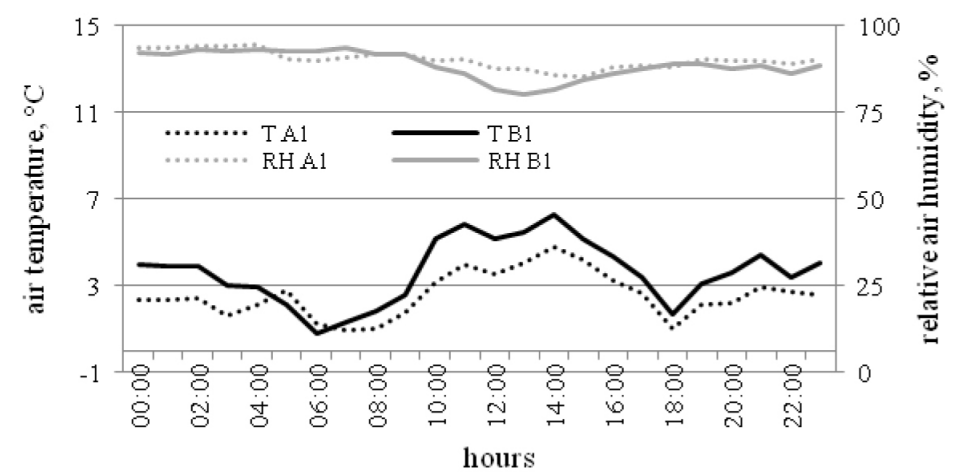

b)

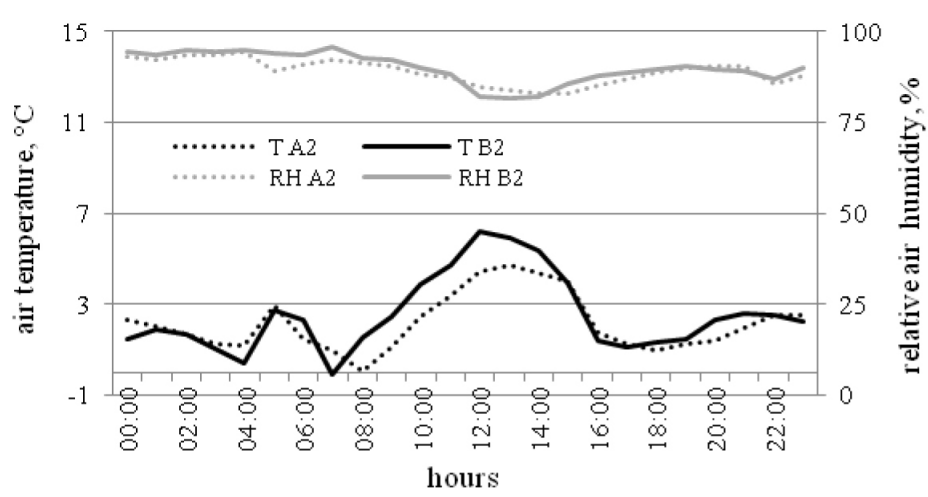

c)

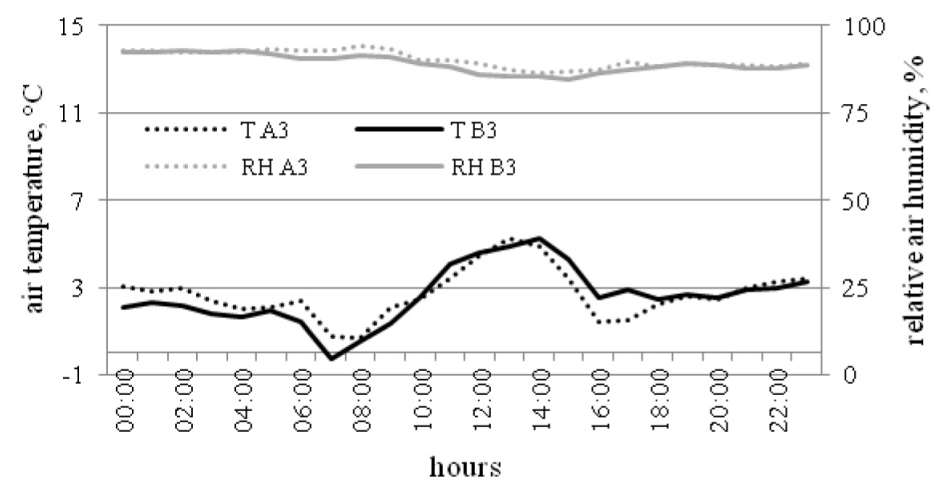

Figure 4. Hourly average air temperature and relative humidity values in barn A and B on 19 December 2013; a) measurement points $\mathrm{A} 1$ and $\mathrm{B} 1, \mathrm{~b})$ points $\mathrm{A} 2$ and $\mathrm{B} 2$, c) points $\mathrm{A} 3$ and $\mathrm{B} 3$ 
On the warm day (26th December) the average outdoor temperature was $10.6^{\circ} \mathrm{C}$. Figure 5 shows the hourly average air temperature and relative humidity values at individual measurement points. The daily average temperature in barn $\mathrm{A}$ was $12.2^{\circ} \mathrm{C}$ and in barn $\mathrm{B}-12.4^{\circ} \mathrm{C}$. The air temperatures at different measurement points were similar; lower temperatures were noted only at point A2 in the afternoon and evening. Relative humidity values in barn A did not differ significantly between the measurement points [max. difference $0.8 \%$ ]. On the other hand, in barn B, a difference of almost $2 \%$ was observed between points B1 and B3 (Fig. 5).
A detailed analysis of two characteristic days during the study period indicated that in warm days the patterns of air temperature, relative humidity changes were similar in both barns, and the hourly average difference amounted to circa $0.3^{\circ} \mathrm{C}$. On a cold day, when the outdoor air temperature fell below $0^{\circ} \mathrm{C}$, there was a difference in temperature between both barns. The difference between the measurement points $\mathrm{A} 3$ and $\mathrm{B} 3$ was only $0.1^{\circ} \mathrm{C}$, whereas the difference between the $\mathrm{A} 1$ and $\mathrm{B} 1$ points reached $1.1^{\circ} \mathrm{C}$. The differences in thermal conditions in the barns could result from the position of the buildings towards cardinal points. Points B1 and A1 were located in the

a)

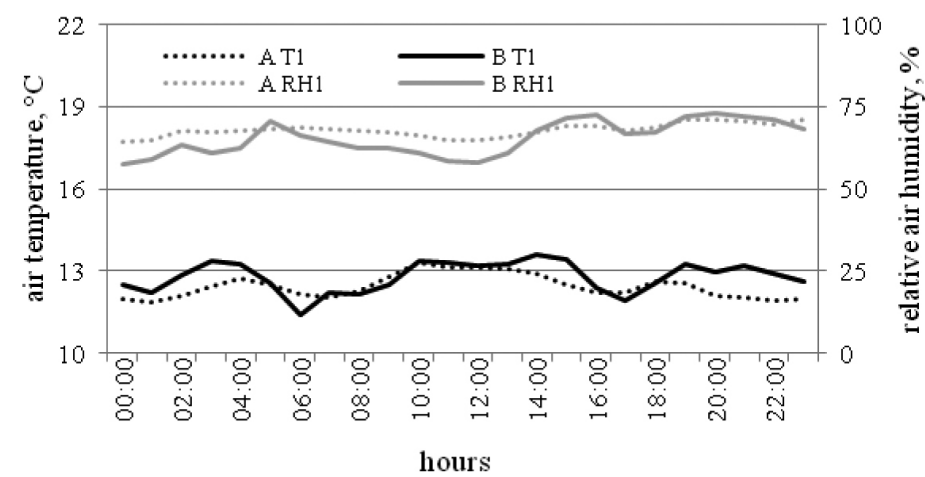

b)

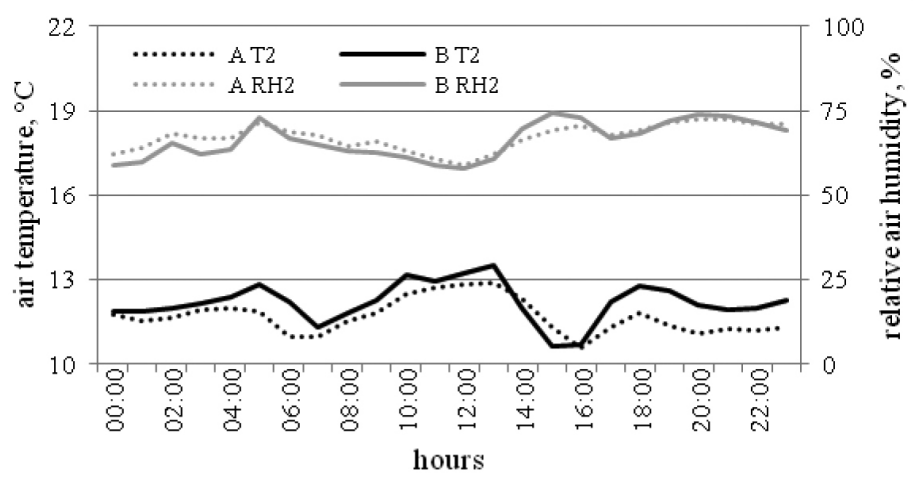

c)

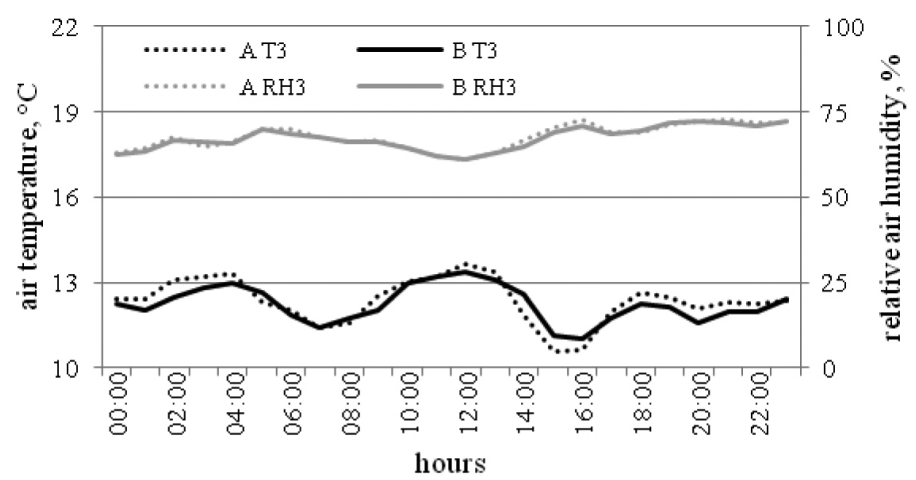

Figure 5. Hourly average air temperature and relative humidity values in barn A and B on 26th December 2013; a) measurement points $\mathrm{A} 1$ and $\mathrm{B} 1, \mathrm{~b})$ points $\mathrm{A} 2$ and $\mathrm{B} 2$, c) points $\mathrm{A} 3$ and $\mathrm{B} 3$ 
leeward part of the building, which was additionally sunlit during the midday hours.

\section{DISCUSSION}

The analysis of the daily average temperature in Poland in 1951-2000 demonstrated its increase by $0.18^{\circ} \mathrm{C}$ per decade [Kożuchowski and Żmudzka, 2001]. However, extension of the analysis by 13 years (1951-2013) indicated a greater rate of air temperature rise amounting to $0.21{ }^{\circ} \mathrm{C}$ [Graczyk et al. 2017]. In particular, a sharp increase in the average temperature in Poland was observed in the second half of the $20^{\text {th }}$ century and was estimated at $0.9^{\circ} \mathrm{C}$. Notably, the rise in air temperature in the winter season is a hallmark of these processes [Kirschenstein and Baranowski, 2009], especially in February and March. The increase in winter temperature is considered to be one of the main causes of warming in Poland [Kożuchowski and Żmudzka, 2001]. The results obtained by the authors of this research confirmed these relationships. The 2013/2014 winter season was warmer than in the preceding years. The increase in the daily average temperature in Bielsko Biala between 2012/2013 and 2013/2014 seasons amounted to $4.9^{\circ} \mathrm{C}$, which is a substantial difference. It should be underlined that in the period when the measurements were conducted, only 5 days showed the daily average temperature below $0^{\circ} \mathrm{C}$ while the obtained average for this period was higher by $8^{\circ} \mathrm{C}$ than the multi-annual average. On the basis of this observation, it can be concluded the study happened to be performed during an atypically warm winter. It was reflected by the air temperatures recorded in both barns, which rarely dropped below $0^{\circ} \mathrm{C}$.

The analysis of the study results revealed that the changes in the atmospheric air temperature and relative humidity did not directly correlate with the changes in these parameters in the barn. The barns with curtain sidewalls are such atypical farm facilities that the indoor microclimate assessment, apart from the climatic conditions, also has to account for the heat emitted by animals. The heat emitted by cows is a factor which depends on the caloric potential of feed, but most of all, on the milk yield [Pedersen and Sallvik, 2002]. These authors reported that the high-yielding cows generate more heat than the dry cows, irrespective of the ambient temperatures. It is concordant with data published by Purwanto et al. [1990], who estimated that the cows with milk yields of $18.5 \mathrm{~kg} / \mathrm{d}$ and $31.6 \mathrm{~kg} / \mathrm{d}$ had $27.3 \%$ and $48.5 \%$ greater metabolic heat production when compared to the dry cows.

On the basis of the calculated value of average heat emission from cows in both barns, it can be concluded that the differences in temperature at different measurement points in barn $\mathrm{A}$ and $\mathrm{B}$ and also the differences in the daily average temperatures between measurement points were caused by the spatial distribution of cows with different milk yield. Barn B housed the cows with a higher milk yield than barn A. The heat emission from cows to the environment was by an average of $180 \mathrm{~W}$ higher in barn B. For this reason, the air temperature in barn B was usually higher than in barn A. However, to perform a more detailed analysis of the effect of heat emitted by cows on the fluctuations of the indoor air temperature in the barn, it would be recommended to take into account the diurnal changes in the heat production by cows and the variability of ambient temperature because these factors are crucial for the heat exchange between an animal and indoor barn space [Lees et al., 2019].

The difference in the orientation of the barns in relation to each other and towards the cardinal points was the next factor that could influence the obtained results. As reported by Angrecka et al. [2017], these factors are also essential for the barn microclimatic conditions. The air temperatures on the south side are higher than on the north side due to a longer exposure of the south side to sunshine during the day in winter. It is also significant that the studied buildings were low and small-volume, situated within a very compact farm complex. According to [Jones et al., 2015], such design of farm facilities limits ventilation of the buildings, thereby contributing to an increase in the indoor air temperature in the barn and, most of all, to elevation of the temperature perceived by cows. It can be expected that the compact layout and thus, the reduced ventilation of the farm also contributed to the improvement of microclimatic conditions in the barns during the analyzed winter season.

Early forecasting of microclimatic conditions enables to limit their negative impact on the cow welfare. Consequently, in the studied barns it was observed that the microclimatic conditions were not dangerous for the animal welfare.

A very warm winter, when the average temperature was higher compared with the multi-annual 
average, and also the influence of heat emitted by cows minimize the impact of low temperatures that can adversely affect the microclimatic conditions in open barns. The results obtained inside two barns indicate that the microclimatic conditions can be variable in the same building, which was confirmed by the studies conducted by Herbut [2013]. In the researched example, the barns layout had a significant impact on the temperature in winter. It was observed that in some areas the temperature and relative humidity values fluctuated over a 24-hour period.

\section{CONCLUSIONS}

On the basis of the obtained measurement results, it can be concluded that the housing conditions in the barns were suitable for the thermal comfort of dairy cows during winter at Poland. However, there were differences in the microclimate parameters between the barns; higher temperatures were noted in barn B.

Variability and differences between the barns depended on the outdoor air temperature, heat emitted by cows, orientation towards the cardinal points and farm layout. The results also indicate the need for defining the microclimatic conditions in different areas inside the barn, in relation to variable atmospheric conditions. Owning to a variety of factors determining conditions in the barn, such as the number of animals, emitted heat, geometry and volume of the barn, it was found that each barn requires individual examination of microclimate.

The dairy cow comfort in winter is assessed mostly based on the daily measurements of air temperature and relative humidity. However, it is recommended to estimate the air flow velocity, exposure to solar radiation in different barn zones, and the influence of heat emitted by cows. This would also help to establish the guidelines for the design of new barns in the context of architectural and spatial solutions.

\section{Acknowledgements}

The research was financed by the Ministry of Science and Higher Education of the Republic of Poland by statutory activity.

\section{REFERENCES}

1. Angrecka S., Herbut P., Nawalany G., Sokołowski P. 2017. The impact of localization and barn type on insolation of sidewall stalls during summer. Journal of Ecological Engineering, 18(4), 60-66

2. Adamczyk K., Górecka-Bruzda A., Nowicki J., Gumułka M., Molik E., Schwarz T., Earley B., Klocek C. 2015. Perception of environment in farm animals - a review. Annals of Animal Science, 15, 565-589.

3. DeVoe K.R. 2017. Climate dependent heat stress mitigation modelling for dairy cattle housing. Graduate Theses and Dissertations Iowa State University Capstones, Theses and Dissertations.

4. Gaworski M., Kowalska M. 2013. Effect of maintenance system on the selected aspects of dairy cattlehealth. Annals of Warsaw University of Life Sciences-SGGW. Agriculture, 62, 63-70.

5. Graczyk D., Pińskwar I., Choryński A., Szwed M., Kundzewicz Z.W. 2017. Changes in air temperature in Poland (in Polish). Climate changes and their impact on selected sectors in Poland, 47-59.

6. Herbut P. 2013. Temperature, humidity and air movement variations inside a free stall barn during heavy frost. Annals of Animal Science, 13(3), 587-596.

7. Herbut P., Angrecka S., Nawalany G. 2013. Influence of wind on air movement in a free stall barn during the summer period. Annals of Animal Science, 13(1), 109-119.

8. Herbut P., Angrecka S. 2015. Experimental and model analysis of mechanical ventilation of a milking parlor in summer. Transactions of the ASABE, 58(4), 1079-1086.

9. Jones D.D., Friday W.H., De Forest S.S. 2015. Natural Ventilation for Livestock Housing. Purdue University - Purdue e-Pubs.

10. Kadzere C.T., Murphy M.R., Silanikove N., Maltz E. 2002. Heat stress in lactating dairy cows: a review. Livestock Production Science, 77, 59-91.

11. Kirschenstein M., Baranowski D. 2009. Annual fluctuations and trends of their changes air temperature in Koszalin (in Polish). Słupskie Prace Geograficzne, 6, 167-178.

12. KundzewiczZ. W., Matczak P. 2012. Climate change regional review: Poland. WIREs Clim Change, 3, 297-311.

13. Kożuchowski K., Żmudzka E. 2001. Warming in Poland: the scale and seasonal distribution of temperature changes in the second half of the 20th century (in Polish). Przegląd Geofizyczny, 46(1-2), 81-90. 
14. Lees A.M., Sejian V., Wallage A.L., Steel C.C., Mader T.L., Lees J.C., Gaughan J.B. 2019. The Impact of Heat Load on Cattle. Animals, 9(6): 322.

15. Pedersen. S., Sallvik K. 2002. Climatization of Animal Houses Heat and moisture production at animal and house levels. Research Centre Bygholm, Danish Institute of Agricultural Sciences.

16. Pilatti J. A., Vieira F. M. C., Rankrape F., Vismara E.S. 2019. Diurnal behaviors and herd characteristics of dairy cows housed in a compost-bedded pack barn system under hot and humid conditions. Animal, 13, 399-406.

17. Pinto S., Hoffmann G., Ammon C., Amon B.,
Heuwieser W., Halachmi I., Banhazi T., and Amon T. 2019. Influence of barn climate, body postures and milk yield on the respiration rate of dairy cows. Annals of Animal Science, 19(2), 469-481.

18. Purwanto B., Abo Y., Sakamoto R., Furumoto F., Yamamoto S. 1990. Diurnal patterns of heat production and heart rate under thermoneutral conditions in Holstein Friesian cows differing in milk production. The Journal of Agricultural Science, 114: 139-142.

19. Teye F.K., Hautala M., Pastell M., Praks J., Veermäe I., Poikalainen V., Pajumägi A., Kivinen T., Ahokas J. 2008. Microclimate and ventilation in Estonian and Finnish dairy buildings. Energy and Buildings, 40, 1194-1201. 